\title{
The Nutritional and Health Benefits of Kiwiberry (Actinidia arguta) - a Review
}

\author{
Piotr Latocha ${ }^{1}$
}

Published online: 7 October 2017

(C) The Author(s) 2017. This article is an open access publication

\begin{abstract}
The kiwiberry (Actinidia arguta) is a new product on the market that is enjoying growing consumer acceptance around the world. This widespread interest has created increased demand for identification of the kiwiberry's nutritional health benefits. Containing over 20 essential nutrients and a range of vitamins, the kiwiberry comes near the top of fruits classed as superfoods. It is one of the richest sources of vitamin $\mathrm{C}$ with up to $430 \mathrm{mg} / 100 \mathrm{~g}$ fresh weight (FW) and is considered the richest dietary source of myo-inositol (up to $982 \mathrm{mg} / 100 \mathrm{~g} \mathrm{FW}$ ). The kiwiberry is also one of the richest sources of lutein (up to $0.93 \mathrm{mg} / 100 \mathrm{~g} \mathrm{FW}$ ) in commonly consumed fruit. Furthermore, containing up to $1301.1 \mathrm{mg} /$ $100 \mathrm{~g} \mathrm{FW}$ phenolics and significant amounts of the essential minerals of potassium, calcium and zinc, the kiwiberry rates very highly as a 'healthy food'. The type and number of this fruit's medicinally promising nutrients have motivated ongoing investigations into its antioxidant, anti-tumour and antiinflammatory properties. Early research has pointed to the kiwiberry being a very promising treatment for some cancers and health issues involving the gastrointestinal system, hypercholesterolemia and certain cancers. A pharmaceutical composition of A. arguta, A. kolomikta, and A. polygama extracts has already been registered for the prevention and treatment of some immune (inflammatory) mediated diseases, as well as
\end{abstract}

Electronic supplementary material The online version of this article (https://doi.org/10.1007/s11130-017-0637-y) contains supplementary material, which is available to authorized users.

Piotr Latocha

piotr_latocha@sggw.pl

Department of Environmental Protection, Faculty of Horticulture,

Biotechnology and Landscape Architecture, Warsaw University of

Life Sciences - SGGW, Nowoursynowska 159,

02-776 Warsaw, Poland the treatment of some non-allergic inflammatory diseases. This paper reviews and highlights the limited nutritional and therapeutic information currently available on the kiwiberry, a minor fruit possessing such major properties.

Keywords Hardy kiwifruit - Chemical composition · Antioxidant activity $\cdot$ Allergy $\cdot$ Superfood $\cdot$ Functional food

$\begin{array}{ll}\text { Abbreviations } \\ \text { AA } & \text { Antioxidant activity } \\ \text { AAE } & \text { Ascorbic acid equivalent } \\ \text { ABTS } & \text { 2,2'-azinobis(3-ethylbenzothiazoline- } \\ & \text { 6-sulfonic acid) } \\ \text { CE } & \text { Catechin equivalents } \\ \text { CUPRAC } & \text { Cupric reducing antioxidant power } \\ \text { DPPH } & \text { 2,2-diphenyl-1-picrylhydrazyl } \\ \text { FRAP } & \text { Ferric-reducing/antioxidant power } \\ \text { GAE } & \text { Gallic acid equivalent } \\ \text { GSH-Px } & \text { Glutathione peroxidase } \\ \text { IgE } & \text { Immunoglobulin class E } \\ \text { LPS } & \text { Lipopolysaccharide } \\ \text { CH } & \text { Hydroxyl radical } \\ \text { ORAC } & \text { Oxygen radical absorbance capacity } \\ \text { PG102 } & \text { Water-soluble extract prepared from } \\ & \text { Actinidia arguta } \\ p \text { NA } & \text { p-nitroanilide } \\ \text { RAE } & \text { Retinol activity equivalents } \\ \text { SOD } & \text { Superoxide dismutase } \\ \text { TAA } & \text { Total ascorbic acid content } \\ \text { TDF } & \text { Total dietary fibre } \\ \text { TE } & \text { Trolox equivalent } \\ \text { TPC } & \text { Total phenol content } \\ \text { UPLC-PDA } & \text { Ultra performance liquid chromatography } \\ & \text { - photodiode array detection } \\ & \end{array}$




\section{Introduction}

Human diets rich in fruit and vegetables are considered to be the healthiest. Novel fruits and berries are increasingly being introduced onto the local and world food stage. It is commonly accepted that these fruits are an important and healthy source of biologically active substances, including vitamins, phenolics, carotenoids and minerals, and that they promote quality of life $[1,2]$. In recent years, there has been growing interest in lesser known fruits such as cornelian cherry, honeysuckle, hawthorn, chokeberry, rowanberry, elderberry, sea buckthorn, medlar, elder, bilberry and kiwiberry, all fruits that are unusually rich in health-promoting compounds. Some of them can be consumed fresh while others are eaten after processing $[3,4]$. The main driver behind their introduction is increased demand for exotic tastes coupled with a unique and healthy eating experience.

Kiwifruit is the main representative of the Actinidia genus. It is known worldwide and highly appreciated for its delicious taste and health-promoting properties [5]. The other edible and very promising Actinidia species is A. arguta (Siebold et Zucc.) Planch. ex Miq., also known as kiwiberry, hardy kiwi, baby kiwi or mini kiwi. This exotic species is very interesting and promising given the horticultural advantages it has over kiwifruit, especially its high frost hardiness (down to $-30{ }^{\circ} \mathrm{C}$ in midwinter) and relatively short vegetation period. This capacity for the kiwiberry to grow in a shorter growing season in colder climates makes it an alternative to the warmer climate kiwifruits of New Zealand, potentially allowing it to become the first Actinidia to be commercially cultivated in colder north European countries [6]. The kiwiberry has been researched in some countries since the middle of the twentieth century, but its commercial production is relatively new and began on a small scale in the US and some European countries in the 1980s and 1990s. Currently the kiwiberry is commercially cultivated in several countries including the US, Chile, New Zealand, Australia, China and most European countries, e.g., France, Belgium, Italy, the Netherlands, Switzerland, Austria, Poland and Germany [7, 8]. Being a vine, Actinidia arguta requires special support for growth and high-quality fruit production, Fig. 1 (online resource). Considered a niche product, the total worldwide kiwiberry crop is estimated to be about $1600 \mathrm{t}$ per year. About half of this is produced in the US, while the second largest group of producers is SCAAP Kiwifruit France, the owner of the Nergi ${ }^{\circledR}$ brand, which produces more than $300 \mathrm{t}$ per year. Another strong group of kiwiberry growers is connected to Ghent University in Belgium and it produces more than $200 \mathrm{t}$ per year in several European countries. In New Zealand, kiwiberry cultivation is concentrated in the Bay of Plenty, with the annual crop estimated to be about $160 \mathrm{t}$. Generally, the world area of kiwiberry cultivation and the annual crop is slowly but steadily increasing. A spectacular increase has only been observed in China, where more than 1200 ha of new plantations have been recently established.

In contrast to the kiwifruit industry being dominated by one cultivar, Hayward, there are many different kiwiberry cultivars, although not all of them have the same commercial potential [9]. Patented cultivars such as Hortgem Tahi, Hortgem Rua or Takaka Green are commonly cultivated in New Zealand. Its fruit is predominantly green without any blush. In the US, the cultivar Ananasnaya, with a strong red blush, is the most extensively grown, but other selections, such as Passion Popers and Aloha Annas, are also cultivated. In Europe, two cultivars are commonly commercially cultivated: Weiki, which is very similar in appearance to Ananasnaya, and Geneva which has spherical green fruit and a weak reddish-brown blush. Finally, in China local cultivars such as Huan no. 1, Long into the 2nd or Quebec Green (entirely green) are the most popular.

A. arguta are small grape-sized fruit, with a thin, edible and predominantly green skin, but some red-coloured cultivars are also available - Fig. 1 (online resource). The fruit is very aromatic with a sweet, intense flavour that has been compared to blackcurrant, pineapple, ripe strawberry, pear, banana, melon and other tropical flavours [10] and can be used for eating fresh and/or for jam and wine.

In light of the growing consumer acceptance of kiwiberry fruit worldwide, there has been an increased focus on identifying the health benefits derived from its consumption. In recent years, the number of scientific publications related to Actinidia arguta has increased significantly. Current research by various scientific institutions points to kiwiberry, similar to kiwifruit, being one of the most nutritionally rich fruits in the world. It is considered to be nature's perfect fruit because it is an excellent source of antioxidants. Most nutritional research conducted on the kiwiberry compares it to the more familiar kiwifruit. Unfortunately, however, there are currently no published scientific findings or comparisons.

Kiwifruit and papaya fruit are considered the most nutrientdense fruits among commonly consumed fruits and are usually referred to as "healthy fruit" [5]. The concentration of such a large number of different compounds in a single fruit is rare. A great advantage of the kiwiberry (over kiwifruit) is its delicate, edible grape-like skin, which contains up to 15 times more antioxidants than the fruit pulp [11, 12]. In contrast to the kiwiberry, kiwifruit requires a tough, fuzzy, unpalatable skin to be peeled prior to eating.

The kiwiberry is considered an excellent source of vitamin $\mathrm{C}$, vitamin $\mathrm{B}_{8}$ (myo-inositol), lutein, $\beta$-carotene, chlorophylls, enzyme actinidin and antioxidants, as well as dietary fibre. It is also a good source of vitamins A and E and some minerals (potassium, calcium, magnesium, copper, iron, manganese), while also containing meaningful amounts of vitamin $\mathrm{B}_{6}$ and other vitamins and minerals. Presently, many nutritional 
components of the kiwiberry remain unstudied and await further analysis.

Considerable published research describes the kiwiberry as having a similar chemical composition to kiwifruit, but containing significantly higher proportional amounts of particular compounds [13, 14]. Therefore, on a given weight basis, kiwiberry could have significantly greater health benefits. Demand for natural foods rich in biologically active compounds is ever increasing. The derived health benefits are proven to be more effective when these compounds occur together [15]. It should be pointed out that the chemical composition of the kiwiberry is not uniform and genetic variability, various aspects of cultivation, harvesting, storage and processing, as well as many environmental factors (e.g., soil fertility, water availability, temperature and insolation) may affect the chemical and nutritional properties of this fruit [16-18].

\section{Kiwiberry Nutrition}

To address the complexities of changes in composition resulting from multiple factors, a large number of samples should typically be analysed using standardised methods. In the main, chemical analyses are conducted on fruit ripened to a "ready-to-eat" state to ensure that the data are reflective of what would normally be consumed. The average amounts of chemical compounds in kiwiberry versus kiwifruit are summarised in Table 1 (online resource).

\section{Basic Chemical Properties (Dry Matter, Soluble Sugar, Pectins, Organic Acids, Titratable Acidity, pH, Ash, Fibre and Protease)}

Kiwiberry dry matter (DM) content depends on the cultivar and the growing conditions but, according to available research, varies between 14.6 and $25.5 \%$, in contrast to Hayward kiwifruit having 15.3-17.2\% DM [14, 16, 19-21]. Unlike kiwifruit, the kiwiberry is a good source of pectins. The amounts of pectin vary widely in kiwiberry cultivars and range from 2.17 to $3.30 \%$ [20]. Kiwiberry soluble solid content at eating maturity stage ranges between $12.1-16.8^{\circ}$ Brix and is higher than that of Hayward kiwifruit (13.2$13.8^{\circ}$ Brix) $[19,20]$. Kiwifruit and kiwiberry soluble sugars and organic acid composition is not uniform and may influence fruit palatability [22]. Kiwifruit (A. deliciosa) and kiwiberry (A. arguta) have a similar total concentration of soluble sugars, containing about 8.1-8.8 and 3.9-9.6 g of sugars per $100 \mathrm{~g}$ of fresh weight (FW), respectively [20, 23-25]. The main soluble sugars in A. deliciosa fruits are glucose and fructose, with sucrose present in smaller amounts.
In contrast, sucrose is the predominant sugar in A. arguta berries, followed by glucose and fructose [7, 26, 27].

The balance of sugar and organic acids in kiwifruit and kiwiberry contributes greatly to their sensory qualities [28]. In this regard, most kiwifruits and kiwiberries have citric and quinic acids as their predominant organic acids, followed by malic acid [7, 20, 29]. In contrast to other common fruits, the acid-tasting quinic acid predominates, but the proportion of quinic acid in the kiwiberry is lower than in kiwifruit [25]. According to Wojdyło et al. [20], kiwiberry organic acids, totalling 16.85-21.06 g/100 g FW, consist of citric acid (5.75-9.56 g/100 g FW), quinic acid (4.17-8.20 g/100 g FW), malic acid (1.37-4.34 g/100 g FW), oxalic acid (1.70$3.67 \mathrm{~g} / 100 \mathrm{~g} \mathrm{FW})$, shikimic acid (0.03-0.23 g/100 g FW) and succinic acid (0-0.28 g/100 g FW). Citric acid is the dominant organic acid, accounting for 30-50\% of the total organic acid content. Significantly divergent results have been produced in Japan by Nishiyama et al. [24]. The authors analysed various species of actinidia and determined the content of the three main organic acids (citric, quinic and malic acid) in A. arguta fruit to be $0.54-1.37,0.51-0.73$ and $0.10-0.30 \mathrm{~g} / 100 \mathrm{~g} \mathrm{FW}$, respectively. In contrast to the kiwiberry, Hayward kiwifruit contains only 2.19-2.41 g organic acids in total per $100 \mathrm{~g} \mathrm{FW}$ [24]. The kiwiberry, with a $\mathrm{pH}$ range of 3.1 to 3.6, and kiwifruit, $\mathrm{pH} 3.1$ to 4.0, are both classified as "high acid" foods. Their ash content ranges between 0.62 to $0.94 \%$ for kiwiberry and is $0.61 \%$ for the kiwifruit Hayward [14, 20].

Kiwiberry fruit contains about 2.0-3.8\% TDF and appreciable amounts of proteases. Kiwiberry TDF, expressed as a percentage of FW is similar or higher than kiwifruit, with insoluble fibre and soluble fibre of $2.1-3.1$ and $0.8-1.0 \%$, respectively. The principal protease is cysteine protease actinidin, which acts similarly to the better-known protease papain [5]. Significant differences in actinidin concentration exist among kiwiberry and kiwifruit species and cultivars. Generally, the amounts of actinidin in the three main species (A. deliciosa, A. chinensis and A. arguta) vary at $2.9-4.4,0-5.7$ and $1.6-10.7 \mathrm{mg} / \mathrm{mL}$ of fruit juice, respectively [30]. The protease activity measured for different kiwiberry cultivars varies appreciably from 25.7 to $114.0 \mathrm{nM} p \mathrm{NA} / \mathrm{min}$ and is much higher than for kiwifruit (6.3-10.1 nM $p \mathrm{NA} / \mathrm{min})[30]$.

\section{Vitamins}

Kiwifruit and kiwiberry are rich in various vitamins. Most notably, Actinidia fruits are exceptionally high in ascorbic acid (vitamin C). Amounts may vary considerably between species and cultivars however. The vitamin $\mathrm{C}$ content of the three main species generally varies from 22.8 to $430 \mathrm{mg} / 100 \mathrm{~g}$ FW, with levels in $A$. arguta (kiwiberry) generally being somewhat higher than in A. chinensis and A. deliciosa (both 
kiwifruit) (on average $150 \mathrm{mg}, 103 \mathrm{mg}$ and $65 \mathrm{mg} / 100 \mathrm{~g} \mathrm{FW}$ respectively) [31].

The most popular kiwiberry cultivars in Europe - Weiki, Ananasnaya and Geneva - differ in vitamin C content between 45.4 and $107.7 \mathrm{mg} / 100 \mathrm{~g}$ FW respectively [17]. Some hybrids, e.g., Issai, are especially rich in this vitamin, containing up to $222 \mathrm{mg}$ vitamin C/100 g FW. Unfortunately, the cultural morphological features of 'Issai' limit this hybrid to more noncommercial applications. Some new Chinese kiwiberry cultivars such as Kui Lu can contain up to $430 \mathrm{mg}$ vitamin C per $100 \mathrm{~g}$ FW [32]. The highest amount of vitamin $\mathrm{C}$ has been found in the kiwiberry Actinidia kolomikta, which accumulates up to $1500 \mathrm{mg} / 100 \mathrm{~g} \mathrm{FW}[19,33]$.

Vitamin $C$ is relatively unstable because it is easily oxidised in the presence of oxygen and light and heavy metal ions. However, the kiwiberry and even kiwifruit with its longer shelf life manage to retain their vitamin $\mathrm{C}$ levels well, displaying only a slight reduction over time [7, 34].

In addition to vitamin C, Actinidia berries are a good source of several other vitamins. They contain significant amounts of vitamin B-complex, mainly $\mathrm{B}_{1}(0.01-0.05 \mathrm{mg}), \mathrm{B}_{2}(0.02-0.11 \mathrm{mg})$, $\mathrm{B}_{3}(0.50-1.55 \mathrm{mg}), \mathrm{B}_{5}(3.80-5.60 \mathrm{mg}), \mathrm{B}_{6}(1.10-1.90 \mathrm{mg})$ and $\mathrm{B}_{8}(266-982 \mathrm{mg})$ in $100 \mathrm{~g} \mathrm{FW}$ [24, 35-37]. Unfortunately a literature search failed to locate scientific research on vitamin $\mathrm{B}_{9}$ (folic acid) in the kiwiberry analysis. According to Nishiyama et al. [24], the kiwiberry has levels of myo-inositol (vitamin $\mathrm{B}_{8}$ ) four to six times higher than those of kiwifruit (up to $982 \mathrm{mg}$ and $153 \mathrm{mg} / 100 \mathrm{~g}$ FW respectively). This makes the kiwiberry one of the richest dietary sources of the hexahydric sugar alcohol, an important vitamin B-complex component. A. arguta fruit has almost the highest myo-inositol content of all foods. In some cases myo-inositol may constitute roughly $60 \%$ of all sugars contained in actinidia fruits [38]. The kiwiberry is an important source of vitamin E (4.6-5.3 mg/100 g FW) which, being a fat-soluble vitamin, is believed to be contained predominantly in the seeds. In such a form, this vitamin would not be bioavailable as the seeds typically resist digestion [5]. However, more recent analysis has shown that the main $\alpha$ tocopherol form of vitamin $\mathrm{E}$ is in the flesh, possibly associated with cell membranes, and therefore potentially bioavailable [39]. Unfortunately, to date there are no scientific reports on a vitamin $\mathrm{K}$ analysis of the kiwiberry. Data on the vitamin A content of kiwiberry is sourced from Korea. According to an analysis undertaken at Suwon Women's University Food Analysis Centre, vitamin A calculated as retinol activity equivalents from different kiwiberry cultivars varied from 37.3 to $84.5 \mu \mathrm{g}$ RAE/100 g FW [40].

\section{Phenolic Compounds}

Both kiwifruit and the kiwiberry are fairly significant sources of phenolics, which are commonly considered to be very effective antioxidants. The reported TPC may vary depending on various factors, including the plant's growing conditions and the laboratory's extraction and determination method. The content of Actinidia arguta polyphenols was found to be up to more than three times that of Hayward kiwifruit [41]. In kiwifruit the TPC recalculated as GAE was 41.7-267 mg per $100 \mathrm{~g} \mathrm{FW}$ [17, 37, 41, 42]. Park et al. [42] suggest that the main group of phenolics in kiwifruit are flavonoids, tannins and flavanols. By contrast, the kiwiberry TPC assayed much higher. According to An et al. [43], the kiwiberry contains $118.2-191.6 \mathrm{mg}$ GAE/100 g FW phenolics, including 28.8-40.4 mg CE/ $100 \mathrm{~g} \mathrm{FW}$ flavonoids. Other research has reported the kiwiberry as having phenolics of up to $426 \mathrm{mg}$ as GAE/ $100 \mathrm{~g} \mathrm{FW}[19,44,45]$, but other studies have reported that the kiwiberry TPC calculated as a sum of all identified compounds ranges from 443.2 to $1301.1 \mathrm{mg} / 100 \mathrm{~g} \mathrm{FW}$ and is significantly cultivar dependant [20]. The authors identified flavan-3-ols (based on the UPLC-PDA method) as the major class of polyphenols in kiwiberry fruits, representing between 96 and $99 \%$ of total polyphenolic compounds. Flavonols are the second major class of phenolic compounds (1-4\%), followed by phenolic acids $(0.4$ $0.7 \%)$ and finally anthocyanins $(0-0.8 \%)$. Based on reference standards or mass spectra, the authors identified about 24 different compounds, twenty-two of which were identified for the first time in the fruits of Actinidia. The largest group was flavonols (16 compounds), mainly quercetin and kaempferol derivatives, followed by phenolic acids (seven compounds). Other sources report the kiwiberry to contain gallic acid, chlorogenoc acid, tannic acid, 2,4dihydroxybenzoic acid, caffeic acid, (+)-catechin, (-)-epicatechin, rutin and quercetin $[11,19]$. As the phenolics protect plant organisms against harmful environmental factors, they are found concentrated in the skin/peel of a fruit. With the kiwiberry, the skin or peel is associated with phenolic concentrations that are much higher than in the pulp [12]. The higher amount of phenolics may possibly reflect exposure levels to various environmental stress factors.

\section{Pigments}

Depending on the species and cultivar, Actinidia fruit also contain substantial amounts of different pigments, including carotenoids, chlorophylls, and anthocyanins. Lutein and $\beta$ carotene, both potent antioxidants, are the most concentrated carotenoids of Actinidia fruit. Among commercial Actinidia species, the kiwiberry contains the highest levels of lutein and $\beta$-carotene, up to 0.93 and $0.29 \mathrm{mg} / 100 \mathrm{~g} \mathrm{FW}$, respectively [46]. Occurring in smaller amounts are zeaxanthin $(0.02-$ $0.04 \mathrm{mg} / 100 \mathrm{~g} \mathrm{FW})$, violaxanthin $(0.01-0.12 \mathrm{mg} / 100 \mathrm{~g} \mathrm{FW})$ and trace amounts of $\alpha$-carotene [17, 41]. Significant quantitative differences in these compounds reported in Europe and 
Japan suggest a significant influence of climate and genetic make-up on fruit pigment composition.

Some red fleshed kiwiberry species and cultivars (e.g., A. melanandra and A. arguta or its hybrids) also contain small amounts of anthocyanins. Available research indicates that the total anthocyanin content was the highest in $A$. melanandra (50.4-98.5 $\mu \mathrm{g} / 100 \mathrm{~g} \mathrm{FW}$ ) and red-fleshed A. arguta cultivars (161.2-206.1 $\mu \mathrm{g} / 100 \mathrm{~g} \mathrm{FW),} \mathrm{where} \mathrm{anthocyanins} \mathrm{are} \mathrm{present}$ in the skin, pericarp and core of the fruits [47, 48]. Other research confirms the presence of anthocyanins in some green-fleshed kiwiberry cultivars as well (up to $129.8 \mu \mathrm{g} / \mathrm{g}$ DW) $[20,41]$. Recent research identifies cyanidin-3-Osambubioside as the major anthocyanin in the Ken's Red cultivar of kiwiberry [20].

Another pigment closely associated with the fruit of Actinidia is chlorophyll. The kiwiberry, containing between 2.6 and $4.2 \mathrm{mg} / 100 \mathrm{~g} \mathrm{FW}$, has up to 3.2 times the chlorophyll concentration of kiwifruit (1.3-2.7 mg/100 g FW) [41, 46]. Chlorophyll $a$ is the predominant form in both kiwifruit and kiwiberry $[17,46]$.

\section{Minerals}

The mineral composition of the kiwiberry is quite variable and depends on its genetic features (cultivar) and growing conditions such as soil and weather. The order of the relative quantity of macroelements found in kiwiberry is $\mathrm{K}>\mathrm{Ca}>\mathrm{P}>\mathrm{Mg}>\mathrm{Na}$, and of microelements is $\mathrm{Fe}>\mathrm{Zn}>\mathrm{B}>\mathrm{Mn}>\mathrm{Cu}$. On the basis of available research, the kiwiberry is a good source of potassium, calcium and magnesium [16, 37, 49-51]. Depending on the cultivar and year of cultivation, the kiwiberry may contain 162.7-382 mg K/100 g FW, 51.5-120.1 mg Ca/100 g FW, 31.7-80.2 mg P/100 g FW, 10.0-23.2 mg Mg/100 g FW, and just 1.2-9.6 mg sodium [16]. The concentrations of potassium and magnesium in the kiwiberry are similar to the levels found in Hayward kiwifruit, while kiwiberry calcium concentration is approximately twice that of kiwifruit [14, 52].

The kiwiberry is also a significant source of microelements, containing 0.31-1.15 mg Fe/100 g FW, 0.18-1.45 mg Zn/ $100 \mathrm{~g} \mathrm{FW}, 0.18-0.48 \mathrm{mg} \mathrm{B} / 100 \mathrm{~g} \mathrm{FW}, 0.03-0.24 \mathrm{mg} \mathrm{Mn} /$ $100 \mathrm{~g} \mathrm{FW}$ and $0.05-0.16 \mathrm{mg} \mathrm{Cu} / 100 \mathrm{~g} \mathrm{FW}$. These values usually make the kiwiberry a richer or similar source of these minerals than kiwifruit $[16,50]$. The same proportion of macro- and microelements in different kiwifruit cultivars tested in Iran has been found by Samadi-Maybodi and Shariat [53] and the kiwiberry Mitsu-ko tested in Japan [7]. According to Japanese studies, the content of $\mathrm{K}, \mathrm{Ca}, \mathrm{Mg}$, $\mathrm{Mn}$ and $\mathrm{Zn}$ in $A$. arguta fruit is higher than in Hayward kiwifruit. Similar results for A. arguta have been obtained by Martens [49] and for A. arguta and A. purpurea hybrids by Bieniek [50]. The consistent correlation between micronutrient proportional concentrations of fruits of the Actinidia genus suggests that this is dependent more on its genetic make-up than on growing conditions.

\section{Amino and Fatty Acids}

The kiwiberry also contains amino acids. According to research undertaken by Jin et al. [37], the content of total amino acids in the kiwiberry is 601-1220 mg/100 $\mathrm{g} \mathrm{FW}$, of which 199-414 mg are essential amino acids. The authors identify about 20 different amino acids in the kiwiberry, with the two major amino acids being glutamic acid and aspartic acid Table 1 (online resource).

The lipid content of the kiwiberry is similar to Hayward kiwifruit and is restricted to the seeds almost entirely, with a small level of membrane-associated lipids located within the flesh [14]. The defined fatty acids include 13.9-30.5\% saturated fatty acids and $70.4-85.8 \%$ unsaturated fatty acids. The analysis of fatty acids shows that the major fatty acids in the three kiwiberry cultivars are palmitic acid as a saturated fatty acid and $\alpha$-linoleic acid as an unsaturated fatty acid [37]. This makes its oil of interest for nutritional uses.

\section{Antioxidant Activity}

Given the type and number of this fruit's medicinally promising nutrients, there are ongoing investigations into its antioxidant and anti-inflammatory properties that might help protect against cardiovascular diseases, cancer and other degenerative disorders. Many of the abovementioned bioactive compounds possess free radical scavenging abilities. The kiwiberry AA of scavenging free radicals in the body could help reduce certain diseases thought to be modulated by free radicals [43]. Kiwiberry extracts show stronger antioxidant activity than kiwifruit, as measured by different methods related to different groups of compounds. Just as the kiwiberry's chemical composition differs depending on various genetic and environmental factors, its ability to scavenge free radicals is also variable. Unfortunately, different measurement methods and extraction procedures (the solvents used, the duration and the temperature of extraction) can make these results difficult to compare. The average AA of different extracts from the kiwiberry versus kiwifruit is summarised in Table 2 (online resource).

According to Latocha et al. [17], the AA of kiwiberry hydrophilic extracts based on the ABTS assay ranges from 1.73 to $4.22 \mathrm{mg} \mathrm{AAE} / \mathrm{g} \mathrm{FW}$ on average and is similar to that of kiwifruit (1.83-2.06 mg AAE/g FW). These results are comparable to values obtained by An et al. [43] for the kiwiberry in South Korea (1.10-2.10 mg AAE/g FW). Meanwhile Leontowicz et al. [41], using the same assay and solvent, indicate a much higher AA of the kiwiberry (47.2- 
122.4 $\mu \mathrm{M} \mathrm{TE} / \mathrm{g}$ DW) compared to kiwifruit (13.5-16.1 $\mu \mathrm{M}$ TE/g DW). In contrast, the AA of lipophilic extracts based on the ABTS assay range from 10.8-29.9 and 11.1-13.5 $\mu \mathrm{M} \mathrm{TE} /$ g DW [41] or 0.93-2.64 and 0.95-1.36 mg AAE/g FW [17, 54, Latocha unpubl.] for kiwiberry and kiwifruit respectively, showing great similarity. The second result is comparable to that obtained for oranges (1.42 mg AAE/g FW), but lower than the one for strawberries (4.72 mg AAE/g FW) [54].

The kiwiberry AA measured by the DPPH assay indicates the same proportions as that obtained by the ABTS assay. Leontowicz et al. [41] maintains that both hydrophilic and lipophilic extracts of the kiwiberry (10.5-42.5 and 9.015.7 $\mu \mathrm{M}$ TE/g DW, respectively) show much higher AA than kiwifruit (6.6-7.9 and 6.0-6.9 $\mu \mathrm{M} \mathrm{TE} / \mathrm{g} \mathrm{DW}$, respectively). Other research work undertaken by Fisk et al. [44] in Oregon in the US, Latocha et al. [17] in Poland and An et al. [43] in South Korea, which used the same method for lipophilic kiwiberry extracts, show similar results - Table 2 (online resource). The research performed on selected fruits in Japan [45] show that the kiwiberry AA measured by hydrophilic ORAC assay (88.7-99.7 $\mu \mathrm{M}$ TE/g FW) is more than 13 times higher than that of kiwifruit (5.2-7.1 $\mu \mathrm{M} \mathrm{TE} / \mathrm{g} \mathrm{FW})$ and $30 \%$ higher than blueberry $(65.6 \mu \mathrm{M} \mathrm{TE} / \mathrm{g} \mathrm{FW})$. In turn, the AA of kiwiberry and kiwifruit lipophilic extracts indicate greater similarity (ORAC assay). Other experiments that used CUPRAC and FRAP assays and both types of solvent [41] confirmed that the kiwiberry has significantly higher AA than kiwifruit, irrespective of the assay used. The results of the kiwiberry AA against naturally occurring hydroxyl radicals $(\mathrm{OH})$, which is claimed to be the most reactive form in biology, confirm that kiwiberry extracts can reduce these radicals by up to $70.7 \%$ [17]. Confirmed by considerable additional research, kiwiberry antioxidant activity is strongly correlated with TPC and TAA content in fruits $[16,19,41,45$, $55]$.

\section{Kiwiberry Health Benefits}

Originating in China, Actinidia plants were historically used in folk medicine for the symptomatic relief of numerous disorders, including digestive problems, dyspepsia, rheumatism and haemorrhoids. Various Chinese cancer therapies purportedly also used Actinidia. The potential health and healing benefits connected with kiwifruit come from its rich nutritional composition and the fact that so many different compounds interact synergistically. This nutrient-dense superfood is a source of beneficial vitamins, minerals, and compounds that are essential for good health.

Kiwifruit's therapeutic value in treating certain diseases has been identified and described in various literary sources. One of the best-known benefits of the Actinidia fruit is its support of the gastrointestinal system. Extract of Actinidia fruit has been shown to support the growth of good flora while suppressing harmful flora [56]. Its enzymatic tenderising property has also been shown to help in the digestion of meat in the digestive tract. Taken together, these supporting actions of kiwiberry and kiwifruit facilitate improved digestive tract health. Some digestive health products based on kiwifruit extracts have therefore already been developed and marketed (e.g., Zylax in New Zealand or Kiwi-Klenz in Germany).

Currently there is little research published on the human health benefits of the kiwiberry. Most research to date has been carried out on animal models or in vitro. Pioneering research on the kiwiberry is being conducted in Poland to demonstrate any health benefits identified [57]. The authors have reported that Actinidia fruits demonstrate protective activity against induced hypercholesterolemia in rats. Two kiwiberry cultivars commonly cultivated in Europe Geneva and Weiki - have a much stronger protective effect than the kiwifruit A. deliciosa Hayward or A. eriantha Bidan. The mechanism protecting against cholesterolemia involves changing the expression of genes connected with the metabolism of fat in the liver and aorta. Some in vitro research conducted in China and Korea confirms the high inhibitory effect of different kiwiberry extracts on some lines of human cancer cells such as HepG2 and HT29 [55, 58, 59] and Hep3B and HeLa in vitro [60]. Subsequent research by Yu et al. [59] has demonstrated some promising anti-cancer properties of A. arguta. Specifically, a polysaccharide of A. arguta, identified as AAP-3b, has inhibited human liver cell tumour proliferation in vitro. This inhibition is associated with the growth interruption of liver tumour cells as well as tumour cell death. This research suggests the future potential of healthy A. arguta fruit or constituents for use in anti-tumour treatment. Nishimura et al. [61] have investigated the inhibitory effect of $A$. arguta juice on the mutagenicity of food-derived carcinogens and polycyclic aromatic hydrocarbons. The authors suggest that the components in A. arguta responsible for the antimutagenicity are water-soluble, heat-labile phenolic compounds. These results suggest that components in A. arguta are promising candidates to be chemopreventive agents. Chinese research has shown that $A$. arguta crude alkaloids possess anti-fatigue effects and increase exercise performance in mice [62], therefore A. arguta could be considered as an anti-fatigue dietary supplement (nutraceutical) in the category of functional foods. Korean researchers have found that the ethyl acetate fraction from $A$. arguta, containing physiological phenolics, might enhance drug-induced amnesia through acetylcholinesterase inhibition and neuroprotection [63]. The latest interesting research on the kiwiberry by An et al. [43] investigates its anti-inflammatory effect using a lipopolysaccharide (LPS)-stimulated RAW 264.7 murine macrophage cell line. The authors conclude that kiwiberry extracts suppress the secretion of pro-inflammatory cytokines, including interleukin- 6 and tumour necrosis factor- $\alpha$, from 
LPS-stimulated RAW 264.7 cells, and can be considered a potential anti-inflammatory agent. Cellular-based measurements of antioxidant capacity show that the kiwiberry extracts have cellular antioxidant capabilities. Such cellular antioxidant effects are possibly directly attributed to their antioxidant properties or to the inhibition of free radical generation via their anti-inflammatory effects. Finally, after their micebased kiwiberry research Gan et al. [35] conclude that kiwiberry juice can significantly activate SOD and GSH-Px in red blood cells and enhance liver health remarkably. It can also increase the antioxidative activity of enzymes and reduce peroxidation in ageing organisms, thus delaying the ageing process.

The aforementioned scientific studies provide new insight into the health benefits of the kiwiberry. Furthermore, the cited research demonstrates and advances the potential role of Actinidia arguta extracts in preventative health care.

\section{Kiwiberry Allergy}

The allergenicity of kiwiberry constituents is neither well studied nor understood. Kiwifruit, more widely consumed than the kiwiberry, has been subject to an increasing number of reported allergies as its worldwide popularity grows. Two to $3 \%$ of the human population display hypersensitivity to the actinidin contained in fruit, with the most common allergic reaction symptom being an oral dermatitis. Interestingly, individuals allergic to $A$. deliciosa kiwifruit demonstrated less severe symptoms following consumption of $A$. chinensis kiwifruit. It has been reported that some allergy symptoms can be influenced by other food components consumed along with kiwifruit [64]. Kiwifruit allergy is often cross-reactive with other allergies, such as that to birch and grass pollen. It also appears to have cross-reactivity to the latex sensitivity syndrome. Several constituents of Actinidia fruit have been tentatively identified as allergenic. Specifically, 11 kiwifruit allergens have been registered in the Allergen Nomenclature database. These include the 30-kd cysteine protease Act (Act d1), an enzyme that catalyses the hydrolysis of peptide bonds and is considered to be the main allergen in kiwifruit, 24-kd thaumatin-like protein (Act d2), 26-kd cell wall protein kiwellin (Act d5), and cysteine protease inhibitor cystatin (Act d4). However, recent concerns have expressed that some kiwifruit proteins may have been added prematurely to the database without adequate scientific rigour in assessing allergenicity or only based on potentially unreliable in vitro assays. IgE binding, rather than clinically relevant reactivity, is inappropriately used to confirm allergenicity [65]. Furthermore, some reports indicate that kiwiberry fruit can even protect against some allergy types. According to Park et al. [66], PG102 possesses orally active immune-modulating activity in mice. In research conducted by Park et al. [67, 68], Choi et al. [69] and Kim et al. [70], kiwiberry extracts have effectively reduced the levels of total IgE in treated atopic dermatitis in mice or rats. The same results have also been reported for dogs [71]. Moreover, Kim et al. [72] mention the antiallergic effects of PG102 in a murine ovalbumin-induced asthma model.

Some clinical studies conducted with PG102 have effectively reduced the levels of total IgE in apparently asymptomatic subjects with atopy [73]. Furthermore, other researchers suggest that PG102 has great potential as a safe (with minimal risk of side effects) orally active immune modulator for the therapy of various human allergic diseases [66]. Research undertaken by Korean scientists has led to an intriguing and promising use of kiwiberry extracts in the modulation of the immune response in humans and non-human mammals.

\section{Conclusions}

Given the expanding worldwide acceptance and consumption of the kiwiberry, there has been increased interest in identifying, both quantitatively and qualitatively, those healthpromoting constituents derived from the fruit. In recent years, there has been a significant increase in the volume of published research on the subject of the kiwiberry's nutritional value and health benefits. Much of this research points to and confirms a rich composition of health-promoting ingredients. The kiwiberry (A. arguta) contains over 20 essential nutrients, making it one of the most nutrient-dense fruits there is. In almost every case, the kiwiberry is more nutrient dense in vitamins, minerals, pigments and phenols than kiwifruit, and is one of the richest sources of both vitamin $\mathrm{C}$ and lutein among commonly consumed fruits. The kiwiberry is also considered to be the richest dietary source of myo-inositol (vit $\mathrm{B}_{8}$ ). Along with significant amounts of phenolics and essential minerals (primarily potassium, calcium and zinc), it is clear why kiwiberry deserves its status as a 'health food' or 'superfood'. Some of these chemicals (mainly vitamin $\mathrm{C}$ and phenolics) possess antioxidant activity. Indeed, considerable research now points to the kiwiberry being a promising natural antioxidant. As such, it could prove helpful in preventing diseases caused by free radicals such as Type I diabetes and certain cardiovascular-related diseases. Early research is already confirming the kiwiberry's potential in treating hypercholesterolemia, certain cancer types and some gastrointestinal-related diseases.

Additional health-related properties of the kiwiberry, including immunologic benefits, have not yet been fully researched or described, but such research is certainly warranted given this fruit's growing popularity.

Acknowledgements The preparation of this review was partially supported by the National Centre for Research and Development (NCBR), 
Poland (grant no. PBS3/A8/35/2015). I would like to thank Mr. Henry Bartosiewicz for help with data collection and Robert B. Stewart, DVM, for his helpful comments and proofreading of the manuscript.

\section{Compliance with Ethical Standards}

Conflict of Interest The author declares that there is no conflict of interest.

Human and Animal Rights This article does not contain any studies with human and animal subjects.

Open Access This article is distributed under the terms of the Creative Commons Attribution 4.0 International License (http:// creativecommons.org/licenses/by/4.0/), which permits unrestricted use, distribution, and reproduction in any medium, provided you give appropriate credit to the original author(s) and the source, provide a link to the Creative Commons license, and indicate if changes were made.

\section{References}

1. Paredes-López O, Cervantes-Ceja ML, Vigna-Pérez M, HernándezPérez T (2010) Berries: improving human health and healthy aging, and promoting quality life - a review. Plant Foods Hum Nutr 65: 299-308

2. Moazzen H, Alizadeh M (2017) Effects of pomegranate juice on cardiovascular risk factors in patients with metabolic syndrome: a double-blinded, randomized crossover controlled trial. Plant Foods Hum Nutr 72:126-133

3. Czaplicki S, Ogrodowska D, Zadernowski R, Konopka I (2017) Effect of sea-buckthorn (Hippophaë rhamnoides L.) pulp oil consumption on fatty acids and vitamin $\mathrm{A}$ and $\mathrm{E}$ accumulation in adipose tissue and liver of rats. Plant Foods Hum Nutr 72:198-204

4. Viapiana A, Wesolowski M (2017) The phenolic contents and antioxidant activities of infusions of Sambucus nigra L. Plant Foods Hum Nutr 72:82-87

5. Ferguson AR, Ferguson LR (2003) Are kiwifruit really good for you? Acta Hortic 610:131-138. https://doi.org/10.17660/ ActaHortic.2003.610.16

6. Debersaques F, Mekers O, Decorte J, Van Labeke MC, SchoedlHummel K, Latocha P (2015) Challenges faced by commercial kiwiberry (Actinidia arguta planch.) production. Acta Hortic 1096:435-442

7. Okamoto G, Goto S (2005) Juice constituents in Actinidia arguta fruits produced in Shinjo, Okayama. Scientific Reports ofthe Faculty of Agriculture Okayama University, Okayama. http:// ousar.1ib.okayama-u.ac.jp/files/public/0/2/ 20160527165120358034/94 009 013.pdf. Accessed 15 Feb 2017

8. Wiliams MH, Boyd LM, McNeilage MA, MacRae EA, Ferguson AR, Beatson RA, Martin PJ (2003) Development and commercialization of 'baby kiwi' (Actinidia arguta planch.). Acta Hortic 610: 81-86

9. Cossio F, Debersaques F, Latocha P (2015) Kiwiberry (Actinidia arguta): new perspectives for a great future. Acta Hortic 1096:423434

10. Matich AJ, Young H, Allen JM, Wang MY, Fielder S, McNeilage MA, MacRae EA (2003) Actinidia arguta: volatile compounds in fruit and flowers. Phytochemistry 63:285-301

11. Kim JG, Beppu K, Kataoka I (2009) Varietal differences in phenolic content and astringency in skin and flesh of hardy kiwifruit resources in Japan. Sci Hortic 120(4):551-554
12. Latocha P, Łata B, Stasiak A (2015) Phenolics, ascorbate and the antioxidant potential of kiwiberry vs. common kiwifruit: the effect of cultivar and tissue type. J Funct Foods 19:155-163

13. Nishiyama I (2007) Fruits of the Actinidia genus. Adv Food Nutr Res 52:293-324

14. Drummond L (2013) The composition and nutritional value of kiwifruit. Adv Food Nutr Res 68:33-57. https://doi.org/10.1016 B978-0-12-394294-4.00003-1

15. Yeomans VC, Linseisen J, Wolfram G (2005) Interactive effects of polyphenols, tocopherol and ascorbic acid on the $\mathrm{Cu} 2+-$ mediated oxidative modification of human low density lipoproteins. Eur J Nutr 44:422-428

16. Latocha P, Debersaques F, Decorte J (2015) Varietal differences in mineral composition of kiwiberry (Actinidia arguta). Acta Hortic 1096:479-486

17. Latocha P, Wołosiak R, Worobiej E, Krupa T (2013) Clonal differences in antioxidant activity and bioactive constituents of hardy kiwifruit (Actinidia arguta) and its year-to-year variability. J Sci Food Agric 93:1412-1419

18. Park YS, Im MH, Ham K-S, Kang S-G, Park Y-K, Namiesnik J, Leontowicz H, Leontowicz M, Katrich E, Gorinstein S (2013) 68 $57-64$

19. Latocha P, Krupa T, Wołosiak R, Worobiej E, Wilczak R (2010) Antioxidant activity and chemical difference in fruit of different Actinidia sp. Int J Food Sci Nutr 61(4):381-394

20. Wojdyło A, Nowicka P, Oszmiański J, Golis T (2017) Phytochemical compounds and biological effects of Actinidia fruits. J Funct Foods 30:194-202

21. Du G, Li M, Ma F, Liang D (2009) Antioxidant capacity and the relationship with polyphenol and vitamin C in Actinidia fruits. Food Chem 113:557-562

22. Jaeger SR, Rossiter KL, Wismer WV, Harker FR (2003) Consumerdriven product development in the kiwifruit industry. Food Qual Prefer 14:187-198

23. Bieniek A (2012) Yield, morphology and biological value of fruits of Actinidia arguta and Actinidia purpurea and some of their hybrid cultivars grown in north-eastern Poland. Acta Sci Pol Hortoru 11: 117-130. http://www.acta.media.pl/pl/action/getfull.php?id=3139. Accessed 15 Feb 2017

24. Nishiyama I, Fukuda T, Shimohashi A, Ota T (2008) Sugar and organic acid composition in the fruit juice of different Actinidia varieties. Food Sci Technol Res 14(1):67-73

25. Boyes S, Strübi P, Marsh H (1996) Sugar and organic acid analysis of Actinidia arguta and rootstock-scion combinations of Actinidia arguta. Lebensm Wiss Technol 30:390-397

26. Cui M, Liang D, Wu S, Ma F, Lei Y (2013) Isolation and developmental expression analysis of L-myo-inositol-1phosphate in four Actinidia species. Plant Physiol Biotechnol 73:351-358

27. Park YS, Jung ST, Kang SG, Drzewiecki J, Namiestnik J, Haruenkit R, Barasch D, Trakhtenberg S, Gorinstein S (2006) In vitro studies of polyphenols, antioxidants and other dietary indices in kiwifruit (Actinidia deliciosa). Int J Food Sci Nutr 57(1/2):107-122

28. Latocha P, Jankowski P, Radzanowska J (2011) Genotypic difference in postharvest characteristics of hardy kiwifruit (Actinidia arguta and its hybrids), as a new commercial crop part I. Sensory profiling and physicochemical differences. Food Res Int 44:19361945

29. Marsh K, Attanayake S, Walker S, Gunson A, Boldingh H, Macrae E (2004) Acidity and taste in kiwifruit. Postharvest Biol Technol 32:159-168

30. Yamanaka M, Ooda T, Fukuda T, Nishiyama I (2004) Varietal differences in actinidin concentration and protease activity in fruit juice of Actinidia species. J Jpn Soc Food Sci 51:491-494

31. Nishiyama I, Yamashita Y, Yamanaka M, Shimohashi A, Fukuda T, Oota T (2004) Varietal difference in vitamin C content in the fruit of 
kiwifruit and other Actinidia species. J Agric Food Chem 52:54725475

32. Xiao X-G (1999) Progress of Actinidia selection and breeding in China. Acta Hortic 498:25-35

33. Cesoniene L, Daubaras R, Viskelis P (2004) Biochemical composition of berries of some kolomicta kiwi (Actinidia kolomicta) cultivars and detection of harvest maturity. Acta Hortic 663:305-308

34. Ferguson AR, Macrae EA (1992) Vitamin C in Actinidia. Acta Hortic 297:481-487. https://doi.org/10.17660/ActaHortic.1992. 297.63

35. Gan Z, Zhang D, Zhang Z, Chen Q, Liu H, Ma Z (2004) Nutritional components and aging - delaying action of some wild berries in Changbai mountainous area. J Xi'an Jiaotong Univ (Med Sci) 25(4):343-345. http://caod.oriprobe.com/articles/7549413/ Nutritional_components_and_aging_delaying_action_of_some wild berries .htm. Accessed 15 Feb 2017

36. Jiang CJ (2011) Development of Actinidia arguta as food materials and components available for prevention of lifestyle-related diseases, and its function mechanism. Msc Thesis, Iwate University Graduate School Department of Agronomy Department of Biological Resources Science (Yamagata University). https:// webcache.googleusercontent.com/search? q=cache: aS7tm13NBFwJ:https://yamagata.repo.nii.ac.jp/\%3Faction\% 3Drepository_action_common_download\%26item_id\%3D1945\% 26item_no\%3D1\%26attribute_id \%3D17\%26file_no\%3D1+\&cd= $4 \& \mathrm{hl}=\mathrm{e}$ \& $\& \mathrm{ct}=\mathrm{clnk} \& \mathrm{gl}=\mathrm{au} \& \mathrm{client}=$ firefox $-\bar{b}$. Accessed 15 Feb 2017

37. Jin DE, Park SK, Park CH, Seung TW, Ho J (2014) Nutritional compositions of three traditional Actinidia (Actinidia arguta) cultivars improved in Korea. J Korean Soc Food Sci Nutr 43(12):19421947. https://doi.org/10.3746/jkfn.2014.43.12.1942

38. Boldingh H, Smith GS, Klages K (2000) Seasonal concentration of non-structural carboohydrates of five Actinidia species in fruit, leaf and fine root tissue. Ann Bot 85:469-476

39. Fiorentino A, Mastellone CD, Abrosca B, Pacifico S, Scognamiglio M, Cefarelli G, Caputob R, Monaco P (2009) $\delta$-Tocomonoenol: a new vitamin $\mathrm{E}$ from kiwi (Actinidia chinensis) fruits. Food Chem 115:187-192

40. Kim I-J, Hong D-G, Lee S-J, Park Y-S, Chang Y. (2014) Fruit of Actinidia arguta breed development, cultivation and use http:// www.ares.gangwon.kr/upload/ebook/20.pdf. Accessed 20 Jan 2017

41. Leontowicz H, Leontowicz M, Latocha P, Jesion I, Park Y-S, Katrich E, Barasch D, Nemirovski A, Gorinstein S (2016) Bioactivity and nutritional properties of hardy kiwi fruit Actinidia arguta in comparison with Actinidia deliciosa 'Hayward' and Actinidia eriantha 'Bidan'. Food Chem 196:281-291

42. Park Y-S, Namiestnik J, Verasilp K, Leontowicz H, Leontowicz M, Barasch D, Nemirovski A, Trakhtenberg S, Gorinstein S (2014) Bioactive compounds and the antioxidant capacity in new kiwi fruit cultivars. Food Chem 165:354-361

43. An X, Lee SG, Kang H, Heo HJ, Cho YS, Do K (2016) Antioxidant and anti-inflammatory effects of various cultivars of kiwi berry (Actinidia arguta) on lipopolysaccharide-stimulated RAW 264.7 cells. J Microbiol Biotechnol 26(8):1367-1374

44. Fisk CL, McDaniel MR, Strik BC, Zhao Y (2006) Physicochemical, sensory, and nutritive qualities of hardy kiwifruit (Actinidia arguta 'Ananasnaya') as affected by harvest maturity and storage. J Food Sci 71(3):S204-S210

45. Mikami-Konishide I, Murakami S, Nakanishi K, Takahashi Y, Yamaguchi M, Shioya T, Watanabe J, Hino A (2013) Antioxidant capacity and polyphenol content of extracts from crops cultivated in Japan, and the effect of cultivation environment. Food Sci Technol Res 19(1):69-79

46. Nishiyama I, Fukuda T, Oota T (2005) Genotypic differences in chlorophyll, lutein, and $\beta$-carotene content in the fruit of Actinidia species. J Agric Food Chem 53:6403-6407
47. Montefiori M, Comeskey DJ, Wohlers M, McGhie TK (2009) Characterization and quantification of anthocyanins in red kiwifruit (Actinidia spp.). J Agric Food Chem 57:6856-6861

48. Seagler N (1997) Synthesis and degradation of anthocyanin in Actinidia arguta $\times$ A. melanandra. Acta Hortic 444:523-528

49. Martens F (2010) Nutritionele aspecten van kiwibes (Actinidia arguta). Msc Thesis, Departement Biowetenschappen en Landschapsarchitectuur, Hogeshool Gent, Belgium

50. Bieniek A (2012) Mineral composition of fruits of Actinidia arguta and Actinidia purpurea and some of their hybrid cultivars grown in northeastern Poland. Pol J Environ Stud 21(6):1543-1550. http:// www.pjoes.com/pdf/21.6/Pol.J.Environ.Stud.Vol.21.No.6.15431550.pdf. Accessed 15 Feb 2017

51. Bieniek A, Dragańska E (2013) Content of macroelements in fruits of ukrainian cultivars of hardy kiwifruit and actinidia charta depending on the weather conditions during the phenological phases. J Elem 18(1):23-38. https://doi.org/10.5601/jelem.2013.18.1.02

52. Sivakumaran S, Huffman L, Sivakumaran S, Drummond L (2016) The nutritional composition of Zespri SunGold® kiwifruit and Zespri sweet green ${ }^{\circledR}$ kiwifruit. Food Chem 238:195-202. https:// doi.org/10.1016/j.foodchem.2016.08.118

53. Samadi-Maybodi A, Shariat MR (2003) Characterization of elemental composition in kiwifruit grown in northern Iran. J Agric Food Chem 51:3108-3110

54. Leong LP, Shui G (2002) An investigation of antioxidant capacity of fruits in Singapore markets. Food Chem 76:69-75

55. Zuo L-L, Wang Z-H, Fan Z-L, Tian S-Q, Liu J-R (2012) Evaluation of antioxidant and antiproliferative properties of three Actinidia (Actinidia kolomikta, Actinidia arguta, Actinidia chinensis) extracts in vitro. Int J Mol Sci 13:5506-5518

56. Lee YK, Low KY, Siah K, Drummond LM, Gwee K-A (2012) Kiwifruit (Actinidia deliciosa) changes intestinal microbial profile. Microb Ecol Health Dis 23:18572-18576. https://doi.org/10.3402/ mehd.v23i0.18572

57. Leontowicz M, Leontowicz H, Jesion I, Bielecki W, Najman K, Latocha P, Park Y-S, Gorinstein S (2016) Actinidia arguta supplementation protects aorta and liver in rats with induced hypercholesterolemia. Nutr Res 36(11):1231-1242

58. Jho EH, Kang K, Lee HJ, Kim CY, Shin I-S, Nho CW (2011) Hepatoprotective effects of Actinidia arguta against oxidative stress induced by tert-butyl hydroperoxide. Cancer Prev Res 16(1):74-79. http://pubs.kist.re.kr/handle/ 201004/39677. Accessed 15 Feb 2017

59. Yu X, Liu C, Liu Y, Tan C, Liu Y (2015) Actinidia arguta polysaccharide induces apoptosis in Hep G2 cells. Adv J Food Sci Technol 7(11):857-863

60. Lim S, Han SH, Kim J, Lee HJ, Lee JG, Lee EJ (2016) Inhibition of hardy kiwifruit (Actinidia arguta) ripening by 1 metylocyclopropene during cold storage and anticancer properties of the fruit extract. Food Chem 190:150-157

61. Nishimura M, Okimasu Y, Miyake N, Tada M, Hida R, Negishi T, Arimoto-Kobayashi S (2016) Inhibitory effect of Actinidia arguta on mutagenesis, inflammation and two-stage mouse skin tumorigenesis. Genes Environ 38:25-37

62. Liu Y, Liu C (2016) Antifatigue and increasing exercise performance of Actinidia arguta crude alkaloids in mice. J Food Drug Anal 24:738-745

63. Ha JS, Jin DE, Park SK, Park CH, Seung TW, Bae D-W, Kim D-O, Heo HJ (2015) Antiamnesic effect of Actinidia arguta extract intake in a mouse model of TMT-induced learning and memory dysfunction. Evid Based Complement Alternat Med 2015:876484. https:// doi.org/10.1155/2015/876484

64. Singletary KP (2012) Kiwifruit overview of potential health benefits. Nutr Today 47(3):133-147

65. Lucas JS, Atkinson RG (2008) What is a food allergen? Clin Exp Allergy 38(7):1095-1099 
66. Park E-J, Kim B, Eo H, Park K, Kim Y, Lee HJ, Son M, Chang Y-S, Cho S-H, Kim S, Jin M (2005) Control of IgE and selective TH1 and $\mathrm{TH} 2$ cytokines by PG102 isolated from Actinidia arguta. J Allergy Clin Immunol 116(5):1151-1157

67. Park E, Park K, Eo H (2007) Suppression of spontaneous dermatitis in NC/Nga murine model by PG102 isolated from Actinidia arguta. J Invest Dermatol 127:1154-1160

68. Park HM, Son M-W, Kim D, Kim S-H, Kwon HC, Kim SY (2011) Fatty acid components of hardy kiwifruit (Actinidia arguta) as IL-4 production inhibitor. Biomol Ther 19(1):126-133

69. Choi J, Park B, Kim DH, Pyo MY, Choi S, Son M, Jin M (2008) Blockade of atopic dermatitis-like skin lesions by DA-9102, a natural medicine isolated from Actinidia arguta, in the mg-deficiency induced dermatitis model of hairless rats. Exp Biol Med 233:10261034

70. Kim JY, Lee IK, Son MW, Kim KH (2009) Effects of orally administered Actinidia arguta (hardy kiwi) fruit extract on 2-chloro-1,3,5- trinitrobenzene-induced atopic dermatitis-like skin lesions in $\mathrm{NC} /$ Nga mice. J Med Food 12:1004-1015

71. Marsella R, Messinger L, Zabel S (2010) A randomized, doubleblind, placebo-controlled study to evaluate the effect of EFF1001, an Actinidia arguta (hardy kiwi) preparation, on CADESI score and pruritus in dogs with mild to moderate atopic dermatitis. Vet Dermatol 21:50-57

72. Kim D, Kim SH, Park EJ, Kang CY, Cho SH, Kim S (2009) Antiallergic effects of PG102, a water-soluble extract prepared from Actinidia arguta, in a murine ovalbumin-induced asthma model. Clin Exp Allergy 39(2):280-289

73. Kim SH, Kim S, Lee SH, Park HW, Chang YS, Min KU, Cho SH (2011) The effects of PG102, a water-soluble extract from Actinidia arguta, on serum total IgE levels: a double-blind, randomized, placebo-controlled exploratory clinical study. Eur J Nutr 50(7): 523-529 